\title{
The Prospect of Turboprop Commercial Flight in Indonesia
}

\author{
Nugraha Arifianto, Sigit S. Wibowo
}

\begin{abstract}
:
The transportation between remote cities and different islands in Indonesia needs to be served by aviation. One possibility to connect cities with short distance is by using small aircraft, such as the turboprop aircraft. However, the feasibility of such aircraft should be examined due to its huge investment and profitability. This study tries to determine the route network of turboprop aircraft in Indonesia using Ryerson and Ge's approach (2014) by examining spatial trends for short-haul aviation and on the regional jet routes. The possibility of turboprop flight on the regional jet routes could be assessed by a distance-based and fuel-time trade-off with three scenarios of fuel price. To validate the potential network of turboprop aircraft, binary logit model predict the probability that a route is fit served by a turboprop. This study shows that more than half of the current regional jet routes in Indonesia can be operated by turboprop aircraft. However, the route which farther than its range capability should be operated with regional jet.
\end{abstract}

Index Terms: Indonesia Aviation, Airline network, Turboprops, Regional Jet, Replacement, Emerging market, Value of Time, Logit Model.

\section{INTRODUCTION}

The Indonesian aviation system has been in a period of rapid expansion since 2010. Many airlines operators aggressively expand their business size; at the same time, many cities build their new airport and other transportation infrastructure. The Indonesian government has also constructed extensively many infrastructures to accommodate economic growth. The government also stated that its infrastructure development in a theme of connectivity, air - sea and land would result in lower transportation and logistics cost, efficient distribution, and competing for national products. Land connectivity projects include integrated mass public transportation, road capacity enhancement, new monorail, and railroad. Sea connectivity projects include dry port development, sea-port revitalization, and water transportation development, while air connectivity projects in each region include cargo airport development and one main airport to support economic growth (Ministry of Transportation, 2016).

To accommodate the expansion of air infrastructure, a specific aircraft can be used for under-developed infrastructures, such as limited length of the runway, limited facilities, and small demand. Turboprop aircraft is a type of 70-seater aircraft with two small propeller-jet engines; it has

Revised Manuscript Received on September 22, 2019

Nugraha Arifianto, Faculty of Economics and Business, Universitas Indonesia, Jakarta, Indonesia.

Sigit Sulistiyo Wibowo, Faculty of Economics and Business, Universitas Indonesia, Jakarta, Indonesia. short take-off and landing distance, at which fit the limited infrastructure in remote and rural areas in Indonesia. Turboprop aircraft is relatively smaller aircraft than current popular aircraft (e.g., Boeing 737 or Airbus 320 family). B737 and A320 are regional jet aircraft type with the bigger jet engine (without propeller) than turboprop aircrafts', and their capacity is about 150-200 seats. Furthermore, Indonesia also has highly populated cities, suffering from air traffic congestion problem and fuel cost sensitive. Fuel efficiency issue always becomes a never-ending story when the fuel price is fluctuated and getting high.

This paper examines the possibility of turboprop aircraft given existing conditions in Indonesia using Ryerson \& Ge's approach (2014a). The rest of the paper is as follows. Section 2 provides existing studies on turboprop aircraft and its network. Section 3 describes the research methodology used in this paper. Section 4 discusses the simulation results and their implication. Section 5 concludes.

\section{LITERATURE REVIEW}

The main concern of turboprop aircraft is the passenger cost. A study by Ryerson and Hansen (2010) show the cost comparison between regional jets and turboprop aircraft. Regular jet has low passenger costs compared with turboprops aircraft. However, the turboprop aircraft also has a similarity of narrow-body jets due to their ability to equalize operating and passenger costs when fuel prices are under those generally happened along the study period. Ryerson and Hansen's study also shows the increasing fuel prices could reverse the tendency of regional jets replacing turboprop in short-haul markets.

Using data from the China aviation market, Ryerson and Ge (2014) estimate the tradeoff based on fuel and time for the replacement of regional jets with turboprops aircraft. They find that the cost of all regional jet routes in China can be reduced if substituted by turboprop aircraft.

Going deeper about fuel cost analysis related to the transportation services, Ryerson and Hansen (2010) examine fuel cost structure with heterogeneous demand and variable fuel price. The fuel cost will directly impact to operating cost, and furthermore, when the cost is increasing, it may result in a market demand shifting to other transportation. To hedge against the fluctuated operating cost, an optimal mixed intercity vehicle can help reduce the total operational costs. In building a transportation network, it has some models. For air transportation, there are some common models, such as a hub-spoke model and the other one is the point-point model.

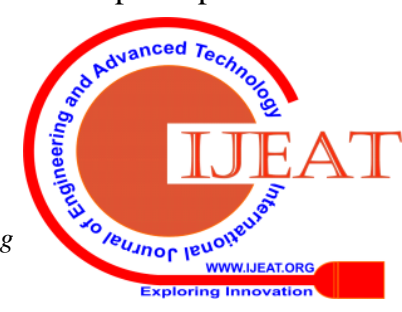


Yang and Chiu (2016) propose a model of the network by doing a sensitivity analysis to investigate the interaction between the stochastic factors. Yang and Chiu's study hub-spoke network design problems in a duopolistic market by assuming the demand is a part of the airline and its competitor's fare strategy. They formulate the competitive hub-spoke network design problem as a two steps stochastic program. The first step is deciding the hub location, which is not be affected by variable pricing strategy. The second step is the decision of route choice and flow assignment, which could be adapted from the competitor's fare setting. The results show that although many airlines are benefiting the model of hub-spoke by its economy of scale and optimized resource, the traveling time is longer. Consequently, it will reduce the number of travelers and also reduce further economic activities. These influences must be traded off along for enhancing social welfare in air network design, as what Han and Zhang (2012) formulated by combining the gravity model and hub choosing problem.

Redondi et al. (2011) identify the method that can help airports to evaluate the number of routes or flight on their connectivity performance. However, the stakeholder who decides which destination to be flown is the airline, whereas the government or local authority may also be considered. Redondi et al. find that the more routes, the better performance on the hub, but still less performance on the remaining network. They also found that the lower connection between the hubs, the higher the connectivity performance. However, the results of this simulation are of interest to airliners. The performance of a network should be measured by the average of flight for a traveler to reach their destination; furthermore, a new route to the hub can enhance the performance of a network.

Other studies use more than one approach. For example, Lordan et al. (2014) use two methods. The first approach is by considering the airline management focus as the top priority. The second one is by considering strategic government policy as the main driver of network design. Both approaches help to see and structure how important the practical implications inherent to the dynamics of air transport network design.

Another side of network design, especially in a developing country, a small type of aircraft such as turboprop is also the issue. Junior et al. (2018) found that there is a correlation between the aircraft type and the willingness to pay of travelers. They examine the hypothesis that people are less willing to pay and fly turboprop, although it is fuel efficient. They find that it is true when the fuel price is falling, so the ticket price for the jet is not so high than the turboprop one.

This study examines the trade-off between fuel and time by using the value of time analysis which existing jet route should be flown by turboprop aircraft.

\section{METHODOLOGY}

On the context of building turboprop networks in Indonesia, the lesson learned from the existing literature is to choose the hub first, then to define the route choice and flow afterward. Building a network is also about connectivity. The more connectivity, the better the quality of the networks.

This study gathers secondary data of flight schedule all over Indonesia and air traffic statistics from Indonesian Ministry of Transportation, and telecommunication statistics from a telecommunication company in Indonesia. The details of data are as follows:

1) The schedule flight data of all aircraft in Indonesia that are registered and published internationally.

2) Route distance and travel time for each route of jet and turboprop aircraft using the average speed of jet and turboprop aircraft.

3) Population data for each city that is constructed by fix-line traffic data by a telecommunication company in the year of 2016.

Refering to Ryerson \& Ge (2014) methodology for China aviation market. However, Indonesia has a different network from China; Indonesia is an archipelago country, whereas China consists of just one mainland. This study will include the all scheduled flight data in Indonesia, included current turboprop aircraft commercial flights that are being operated by Wing Air, Garuda Indonesia, NAM Air, and the others. The following described method will use recent data in early 2019 as the basic data to assess the routes for turboprop aircraft.

To build a turboprop aircraft networks, some approaches could be done, firstly by spatial trends for short-haul aviation. The spatial trend uses the current turboprop aircraft routes. Secondly, replacing the regional jet routes that are very short-haul flights. And the third is by using regression a logit model of population data. Furthermore, use the binary logit model of the population to see the possibility of using turboprop on new routes in Indonesia.

\section{A. Identifying regional jet routes by distance-based}

As the size of the turboprop aircraft is smaller aircraft than regional jet one, so it is logically to be deployed turboprop aircraft on the shortest route that exists. The strategy of this approach is to position the turboprop aircraft on the shortest route possible first. By understanding the geography of Indonesia archipelago, once this method is applied, the flight will be spread to all region in the country. Within this spreading phenomenon some cities that will have more connections to less than $430 \mathrm{~km}$ cities $(25 \%$ of jet aircraft average distance).

As replacing jet aircraft by this route distance strategy, an increase in the number of small hubs and its intensity of connections to be served by turboprop aircraft. However, deployment of turboprop aircraft with a kind of strategy needs to be driven by government master plan in aviation so that airline deploys the proper aircraft type to other right routes by distance strategy.

On this method, it is purely by distance factor. So it is limited, not involving economic factors, such as demand, size of the market, other modes of transportation existence, price, cost, and revenue. This is done to get a glance of the best route choice by its physical size of aircraft; small aircraft should fly on the short route.

Published By: 


\section{B. Calculating fuel and time trade-off in regional jet routes}

It would be pricy to replace regional jet operations with turboprop aircraft. By simple logic, fuel consumed by each flight would decrease flight times (increasing the passenger's cost), this is more because turboprop aircraft use smaller engine then jet one. Monetizing the time and fuel to explore the distance-fuel price trade space between the regional jet and turboprop aircraft to estimate this trade-off. The fuel monetization is straightforward, as the price of fuel is fixed and published. But time monetization requires a metric of Value of Time (VoT). Transportation VoT is typically estimated through discrete selection models that capture how a decision-maker trades time, cost, and other attributes.

VoT is the marginal replacement rate between inputs of time and cost. In other words, VoT is the value of savings or the fuel cost at which used to value the lengthen time. For example, a route is operated by both types of aircraft, regional jet, and turboprop aircraft. Regional jet travels on the route with an amount of fuel and duration of the flight. Meanwhile, turboprop aircraft also fly on that route with less fuel burn than regional jet consumes, but with a longer duration than regional jet takes. So, the lengthen travel time will be valued by the saving of fuel burn cost.

Establishing a VoT is both feasible and complete is a challenge for Indonesia. Indonesia has not been familiar in term of value of time. For this reason, this reseach adopt a metric titled the break-even VoT that formulated by Ryerson $\&$ Ge (2014). VoT model comprises of fuel savings and the lengthened travel time created if a turboprop aircraft is flying a regional jet route. When turboprop aircraft fly on the jet route, it will save some fuel and lengthen travel time, so, when is a route should be replaced or not replaced by turboprop aircraft? It could be determined by the break-even VoT.

The break-even VoT is the maximum value of time for which turboprop aircraft could be still an economically viable option. The break-even VoT is the value of time for Indonesian traveler. And if the amount of time of Indonesia traveler is more significant than the VoT in a route, the regional jet is more preferable than turboprop aircraft. This is because passenger will value the time very valuable, more than the saving of fuel cost.

The metric, termed VoT is formulated as a function of the fuel consumption and travel time of a flight:

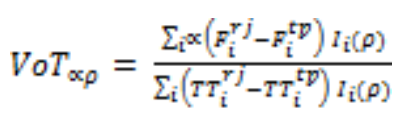

$F_{\mathrm{i}}^{y \tilde{j}}$ Is the estimated fuel consumed in gallons for flight $\mathrm{i}$ on aircraft $\mathrm{k}$ (turboprop aircraft, regional jet $\ni \mathrm{k}$ ) using the equations estimated in (1) and the scheduled flight data. $T T_{i}^{y j}$

Is the estimated travel time for flight $i$ on aircraft $k$ estimated using the average cruise speed for aircraft type $\mathrm{k}$ and the travel distance for the flight $I$ in the scheduled flight data. $\alpha$ is the price of fuel in a \$/gallon. To be considered parametrically from $\$ 6.2 /$ gallon, consistent recent historical Indonesia jet fuel price. $I_{i}(\rho)$ Is an indicator function equal to 1 if the distance of flight I is less than the p-percentile distance across all flights.
After calculating all the VoT of each existing flight both by regional jet and turboprop aircraft, then compare them to VoT for Indonesian traveler. Once the VoT of a route is higher than VoT for Indonesia traveler, it should suggest it flew by turboprop aircraft.

\section{Examining the possible future routes for turboprop aircraft in Indonesia}

Turboprop aircraft is feasible to replace the regional jet network in Indonesia when doing a trade-off between fuel and time. However, nowadays, a regional jet is more familiar and might be more preferable. So next, look for any potential route that might be established in the future by turboprop aircraft. Since turboprop aircraft is a relatively small aircraft, about 70 -seater, then the potential route should be a small size route in terms of demand, or limited in term of operational or geographic in Indonesia.

Following Ryerson and Ge (2014), a binary logit to examine the prospect of turboprop aircraft based on results in the previous section. This model will predict the probability of either turboprop aircraft or jet aircraft be used on a route. At this case, the model will allow us to predict probabilities from a choice set of two, regional jet and turboprop aircraft, or $R J$ and $T P$. This probability will be affected by the aircraft type and attributes of the route in term of size market. So building on numerous studies of the aviation system using discrete choice models to predict the behavior of airlines and air passengers. For each future route, predict the likelihood that it will be served with type $k$ aircraft as a function of each aircraft type attributes and route attributes.

Then use the determined density of each airport and classify each city density into three categories. The three categories are high density $(\mathrm{H})$, medium density $(\mathrm{M})$, and low density (L). High dense if the city has more than 500,000 people in the population, medium dense if the city has around $200,000-500,000$ person, and it is said small dense if it is fewer than 200,000 person in the area. So, next make the city pair of the three categories of density, they are LL, LM, ML, LH, HL, MH, HM, MM, HH. But if assuming that it does not matter about the direction of the flight, the category pair will be just six, LL, MM, HH, LM, LH, MH. This six category pair will be six binary dummy variables reflecting each density pair of the origin and destination.

So, to predict the probability that a route is served with aircraft type k, turboprop aircraft or regional jet will use the formula 3 . The probability is a function of the utility of a route (1) if it is served by both regional jet and turboprop aircraft. The utility in operating aircraft $\mathrm{k}$ on a route as $\mathrm{Vk}$. $\mathrm{Vk}$ then is a non-unit measure of satisfaction or attractiveness.

$$
\begin{aligned}
& P(k)=\frac{e^{V_{k}}}{\sum_{j 3 k} e^{V_{j}}} \\
& V_{k}=\beta_{t t} t t_{k}+I_{k}(r j) \sum_{d} \beta_{d} D_{d}
\end{aligned}
$$

$V_{k}$ Is the probability that, for a single flight on aircraft $\mathrm{k}, \mathrm{k}$ $\ni \mathrm{K}, V_{k}>V_{j} . V_{k}$ is the deterministic utility function for aircraft k. ${ }^{t t_{k}}$ is the travel time on aircraft $\mathrm{k}$. Dd is a binary variable designating the density

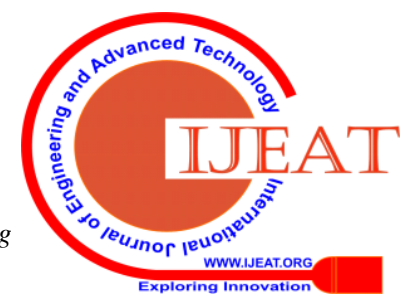


measure for the route, where $\mathrm{d} \ni$ (LL, MM, LM, LH, MH). $\mathrm{HH}$ is the base case. $l_{k}(r j)$ is an indicator function which is one if the observation is for regional get and 0 otherwise.

After applying Equation (3) to all possible future routes in Indonesia, the prediction on routes that might operate turboprop aircraft, and some of them are the new airport or new city that currently still has no air infrastructure yet. So the steps are, first, creating some potential new routes between spokes and hubs by connecting the emerging spokes to emerging hubs; second, calculating the travel time by both turboprop aircraft and regional jet aircraft for these routes great circle distance (by using average cruise speeds established in the previous section) and establish density categorize of the airports.

After the calculation for each route, the probability means the turboprop aircraft portion. So the result is not an absolute number for turboprop aircraft to fly or not. So this is rather a metric like a portion for turboprop aircraft. For example, if an operator flies a route ten times a day, then it is likely two of those flights will use the turboprop aircraft.

\section{RESUlt AND DiscuSSIONS}

On this research, following the methodology has been described in section 3, this section will describe the calculation result and its analysis with the methodology.

\section{A. Analysis of Replacing Regional Jet Routes by Distance based Method}

After doing the simulation under a limitation of the certain distance between two cities in Indonesia which are less than 430 kilometers should be served by turboprops, by sorting and filtering the information from published flight schedule, the results are:

1) Three hundred eighty-four jet flights of all 878 flights in a range of $430 \mathrm{~km}$ need to be replaced by turboprop aircraft.

2) 4 origin-destination (OD) of all 249 (OD) in the range of $430 \mathrm{~km}$ need to be replaced by turboprop aircraft.

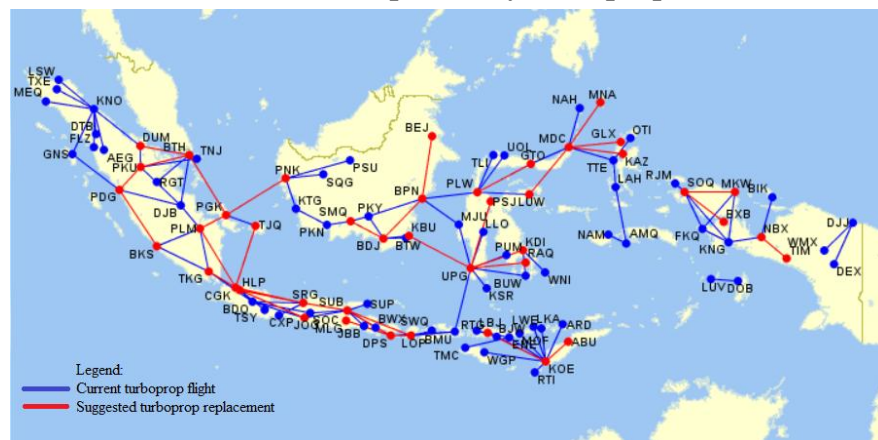

Fig. 1. The Prospect of Jet to Turboprop Replacement in range of 430 Kilometers. Source: authors' calculations, generated using gcmap.com.

\section{B. Analysis of Replacing Regional Jet Routes by Fuel and Time Trade-offs}

The prospect flight route is the same when the fuel price increases from (scenario 1) USD 3/gallons to (scenario 3) USD 5/gallons, shows that the break-even value of time of Indonesia traveler is rather low to accept any fuel price scenarios. This finding also says that Indonesia travelers welcome the prospect flight route of turboprop all over the country.

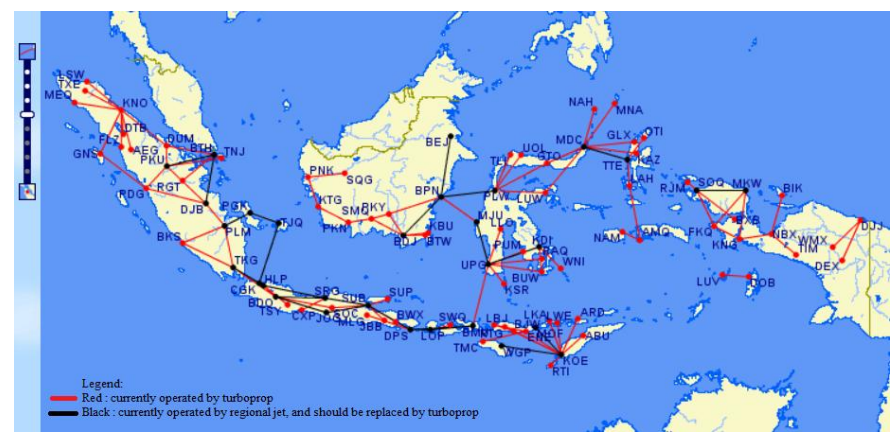

Fig. 2. Candidate Routes for Turboprop Replacement in 25th-percentile Distance ( $\alpha=$ USD 3/gallon). Source: authors' calculations, generated using gcmap.com.

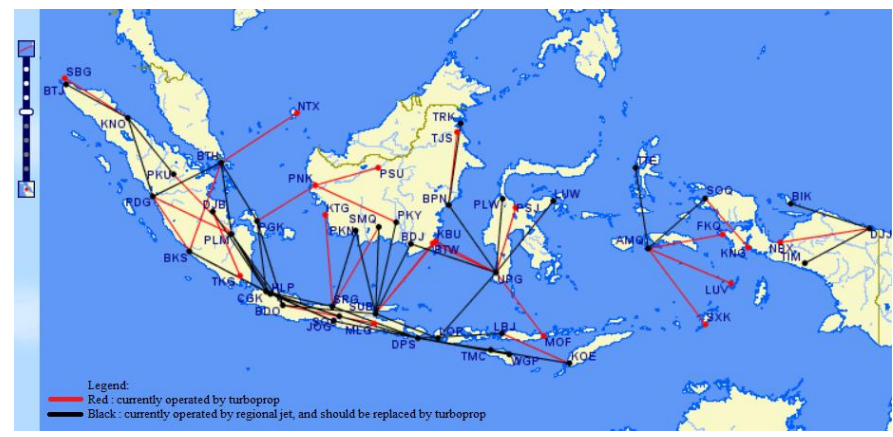

Fig 3. Candidate Routes for Turboprop Replacement in 50th-percentile Distance ( $\alpha=\mathrm{USD} 3 /$ gallon). Source: authors' calculations, generated using gcmap.com.

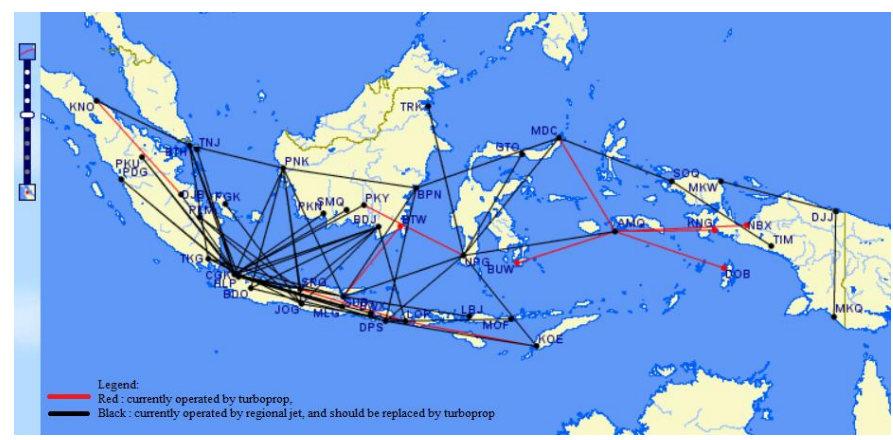

Fig 4. Candidate Routes for Turboprop Replacement in 75th-percentile Distance ( $\alpha=\mathrm{USD} 3 /$ gallon). Source: authors' calculations, generated using gcmap.com.

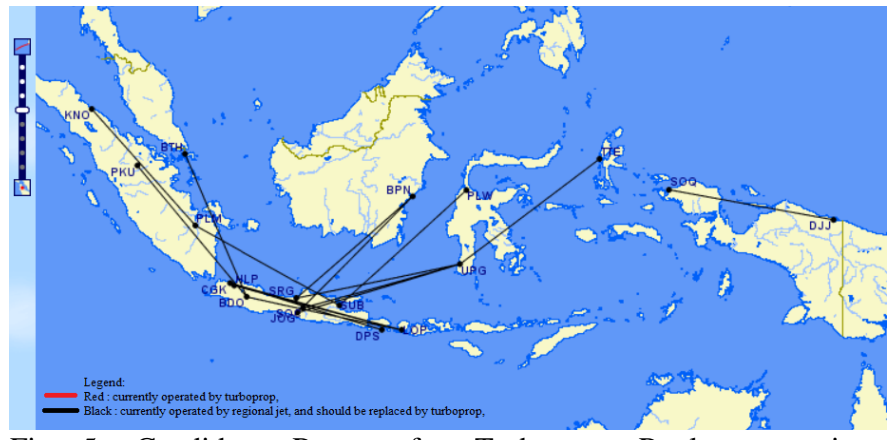

Fig 5. Candidate Routes for Turboprop Replacement in 100th-percentile Distance ( $\alpha=$ USD 3/gallon). Source: authors' calculations, generated using gcmap.com.

Published By: Blue Eyes Intelligence Engineering 


\section{The Prospect of New Routes for Turboprop Flights in Indonesia}

The estimation result of logit model regression is on the regression result table 1 The coefficient of travel time is positive. The interpretation is that for Indonesia, traveler increased travel time increase the utility of a particular aircraft type. Then density variables enter into the regional jet utility function. The interpretation is that for example, the utility of using a regional jet for travel between airports in the low density decreased the utility of regional jet aircraft. This show that turboprop will have a higher value of utility than regional jet when flying at least one region of low density.

Table 1. Logistic Regression Results.

\begin{tabular}{lc}
\hline Parameter & Estimate \\
\hline Travel Time $\left(r_{j}\right)$ & $2.0758^{*}$ \\
& $(1.1352)$ \\
Medium to High density & $0.0447^{*}$ \\
& $(0.2646)$ \\
Low to High density & $-1.3783^{* *}$ \\
& $(0.6165)$ \\
Low to Medium density & -0.9671 \\
& $(1.0619)$ \\
Medium to Medium density & 1.1663 \\
& $(1.0176)$ \\
Low to Low density & -0.5448 \\
& $(0.63769)$ \\
Constant & $-1.9842^{* * *}$ \\
& $(0.3853)$ \\
\hline Observations & 486 \\
McFadden $R^{2}$ & 0.0295
\end{tabular}

Standard errors in parantheses. $* * * \mathrm{p}<0.01, * *<0.05, * \mathrm{p}<0.1$ Source: authors' calculations.

\section{Conclusion}

It can be concluded that Turboprop in Indonesia currently has been right deployed to the shortest range in the range of 430 $\mathrm{km}$, and there are 35 more prospect routes that could be replaced by turboprop aircraft. Based on the value of time of Indonesia travelers, the prospect of turboprop flight is very good that it is suggested to the almost all routes from 25-th percentile to the 100-th percentile of distance. The probability of the new route is between $40 \%$ to $70 \%$ for turboprop, this means that Turboprop has a prospect in the future new routes.
6. Forsyth, P., King, J., and Rodolfo, C. L. (2006). Open skies in ASEAN Journal of Air TransportManagement, 12(3):143-152.

7. Govindasamy, S. (2013). UPDATE 1-Garuda Indonesia plans to double fleet by 2025 . Retrieved from https://www.reuters.com/article/garuda-orders/update-1-garuda-indon esia-plans-to-double-fleet-by-2025-idUSL4N0IZ35B20131114.

8. Han, L. and Zhang, N. (2012). Hub-and-spoke airline network design method and application based on gravity model. Applied Mechanics and Materials, 178-181:1941-1946.

9. Junior, C.H.M., de Arantes Gomes Eller, R., and Oliveira,A.V.(2018). Are passengers less willing to pay for flying turboprops? An empirical test of the "turbo aversion hypothesis", Journal of Air Transport Management, 73:58-66.

10. Ministry of Transportation (2015). Strategic plan. Retrieved from http://dephub.go.id/post/read/rencana-strategis-kementerian-perhubu ngan-2015-2019.

11. Ministry of Transportation (2017). Statistik Perhubungan 2016 Buku I. Jakarta: Kementerian Perhubungan.

12. Lordan, O., Sallan, J. M., and Simo, P. (2014). Study of the topology and robustness of airline route networks from the complex network approach: a survey and research agenda. Journal of Transport Geography, 37:112 - 120.

13. Ma, H., Oxley, L., Gibson, J., and Li, W. (2010). A survey of China's renewable energy economy. Renewable and Sustainable Energy Reviews, 14(1):438 - 445.

14. National Bureau of Statistics of China (2013). National data. retrieved from https://www.data.stats.gov.cn/workspace/index?m=hgnd.

15. Redondi, R., Malighetti, P., and Paleari, S. (2011). New routes and airport connectivity. Networks and Spatial Economics, 11(4):713-725.

16. Ryerson, M. S. and Ge, X. (2014). The role of turboprops in China's growing aviation system. Journal of Transport Geography, 40:133-144.

17. Ryerson, M. S. and Hansen, M. (2010). The potential of turboprops for reducing aviation fuel consumption. Transportation Research Part $D$ : Transport and Environment, 15(6):305 - 314.

18. Ryerson, M. S. and Hansen, M. (2014). Optimal intercity transportation services with heterogeneous demand and variable fuel price. IEEE Systems Journal, 8(4):1161-1171.

19. University of New Mexico (2013). Per capita personal income by state retrieved from https://www.bber.unm.edu/econ/us-pci.htm.

20. Yang, T.-H. and Chiu, T.-Y. (2016). Airline hub-and-spoke system design under stochastic demand and hub congestion. Journal of Industrial and Production Engineering, 33(2):69-76.

21. Yang,T.H.andHuang,Y.(2015). Hub-and-spoke airline network design under competitive market. Journal of Industrial and Production Engineering, 32(3): 186-195.

\section{AUTHOR PROFILE}

Nugraha Arifianto,

I am Nugraha Arifianto currently I am affiliated with Faculty of Economics and Business, Universitas Indonesia, Jakarta, Indonesia.

Sigit Sulistiyo Wibowo,

I am Sigit Sulistiyo Wibowo currently I am affiliated with Faculty of Economics and Business, Universitas Indonesia, Jakarta, Indonesia.

\section{REFERENCES}

1. Alamdari, F. and Mason, K. (2006). The future of airline distribution Journal of Air TransportManagement, 12(3):122-134.

2. Badan Pusat Statistik (2019a). Ekonomi indonesia 2018 tumbuh 5,17 persen. retrieved from https://www.bps.go.id/pressrelease/2019/02/06/1619/ekonomi-indone sia-2018-tumbuh-5-17-persen.html.

3. Badan Pusat Statistik (2019b). Pertumbuhan ekonomi dki jakarta tahun 2018 sebesar 6,17 persen. retrieved from https://jakarta.bps.go.id/pressrelease/2019/02/06/335/pertumbuhan-e konomi-dki-jakarta-tahun-2018-sebesar-6-17-persen.html.

4. Climatetechwiki. (n.d.), Optimising Aviation. Retrieved from https://www.climatetechwiki.org/technology/aviation.

5. Doganis, R. (2006). The Airline Business, Second Edition. Oxford: Routledge. 